\title{
Outcome of Surgical Treatment for Spinal Cord Compression in Patients With Hematological Malignancy
}

\author{
PANAGIOTIS TSAGOZIS, BSC, MD, PHD, HENRIK C.F. BAUER, MD, PHD \\ Department of Orthopaedic Surgery, Karolinska University Hospital, Stockholm, Sweden
}

\begin{abstract}
Background: We investigated the outcome of surgical treatment of patients with radiosensitive hematological malignancies presenting with spinal cord compression.

Methods: Retrospective review of 50 patients who had treatment between 1993 and 2012 .

Results: The neurological outcome was favorable in 35 patients, stable in 12, whereas 3 patients deteriorated. Decompression within 48 hours from referral was associated with a superior neurological recovery $(P=.001)$. Complications were noted in 11 patients, and 6 of these underwent secondary surgery. Early (30-day) mortality was $8 \%$. Radiotherapy was associated with increased incidence of complications $\left(\chi^{2}=0.009\right)$. Patients who had low blood hemoglobin preoperatively as well as those who remained totally bedridden postoperatively had an inferior overall survival rate $(P<.001)$.

Conclusion: Patients with cord compression from hematological malignancy benefit from early surgical decompression. There is an inherent high risk for complications, which increases further if radiotherapy is given. Patients failing to ambulate after surgery have a poor prognosis.
\end{abstract}

Tumor

Keywords: spine, metastasis, surgery, lymphoma, myeloma

\section{INTRODUCTION}

Metastatic spinal cord compression (MSCC) is a devastating event that occurs in $5 \%$ to $14 \%$ of patients suffering from cancer. ${ }^{1}$ The neurological deficit may pose serious threats to the patients' ambulatory capacity as well as to bladder and bowel function, often resulting in paresis and incontinence. Furthermore, mechanical instability or pathological fracture can cause severe pain. ${ }^{2}$ Patients with MSCC are thus prone to have an impaired quality of life and require considerable resources from the health care system in forms of advanced palliative nursing care. Recent developments in the diagnosis and therapy of cancer have improved survival, resulting in an increased need for optimal management. ${ }^{3-5}$

Early studies did not show any benefit of surgery in patients with MSCC as compared with conventional radiation therapy, and the latter remained the standard treatment for decades. ${ }^{2,6}$ There has recently been a shift towards surgery since studies in the 1990s showed that surgical decompression was associated with improved function. ${ }^{7,8}$ This was confirmed in recent prospective series. ${ }^{9-12}$ However, the outcome of surgical treatment of patients with radiosensitive hematological malignancies is largely unknown, because they were mostly excluded from the aforementioned prospective studies and the only data are derived from small retrospective cohorts. $^{13,14}$

We retrospectively reviewed prospectively collected data of 50 consecutive patients surgically treated for MSCC due to lymphoma or myeloma between July 1993 and December 2012, and we documented the treatment outcomes.

\section{PATIENTS AND METHODS}

We reviewed the prospective database of our department and retrieved data for 50 consecutive patients with a diagnosis of myeloma (35 patients, of whom 9 had a solitary plasmocytoma) or lymphoma (15 patients) who were treated surgically between 1993 and 2012. Twenty-three patients presented with metastatic spinal cord compression from a neoplasm of unknown primary localization, and biopsy samples taken during decompression established the diagnosis, whereas 27 patients had a known hematological malignancy. All patients were treated in a multidisciplinary manner, in close collaboration with hematologists who were respon- 
sible for systemic treatment. The study conformed to institutional review board requirements.

There were 19 female and 31 male patients. Median age at operation was 65 years (range, 31-85 years). Mean follow-up was 45 months. Forty-two patients presented with epidural compression of the thoracic spine; 7 patient, of the lumbar; and 1 patient, of the cervical. Imaging was based on magnetic resonance tomography studies or computed tomography. A pathological fracture was documented in 31 patients. Median blood hemoglobin level prior to operation was $120 \mathrm{~g} / \mathrm{dL}$.

The main indication for surgery at our department was patent neurological compromise. ${ }^{15} \mathrm{We}$ rarely operated due to spinal instability, pain, or to prevent neurological compromise in a patient with normal function. Twenty-six patients had lost their ambulatory capacity upon admittance (2, Frankel score A; 9, Frankel B; and 15, Frankel C), 23 could walk with aids (Frankel D). One patient had negligible deficits (Frankel E) and had an open biopsy and laminectomy to verify diagnosis and to prevent an imminent cord compression. All patients, except 1 who was in very poor general condition, had chemotherapeutic treatment for their disease. Radiotherapy was given preoperatively or postoperatively in 33 patients.

Operations were performed by consultant-grade surgeons. Time to surgery was calculated from the moment the patients were admitted for consideration of surgical decompression. Instrumentation was used in 29 patients, whereas 21 patients underwent posterior decompression only. The decision to perform posterior stabilization was individualized and took into account any evidence of biomechanical instability and associated severe pain, as well as the expected survival of the patient. The presence of a pathological fracture was associated with a higher rate of instrumentation $(P$ $=.001)$. The implants used for posterior fixation were the Universal Spine System in 17 patients, the Cotrel-Dubousset in 5 patients and the Isola system in 5 patients, respectively. Anterior decompression and stabilization with a Z-plate was performed in 1 patient and with the Telefix system in another. Routine antibiotic prophylaxis was a 1- to 3-dose regimen of flucloxacillin or clindamycin. Antithrombotic prophylaxis was dalteparin (5000 IE subcutaneously). Patients were allowed to mobilize without any restrictions. Postoperative radiotherapy was given after wound healing (3-6 weeks). Neurological deficits were evaluated according to the Frankel scale. To evaluate the mean neurological outcome, the Frankel scale was arbitrarily converted to an arithmetic score of 1 to 5 . This evaluation was done at 2 different time points: the first one after a median of 2 weeks postoperatively, whereas the second one preceded the last hospitalization or outpatient appointment, at a median of 44 months.

Statistical analysis of the data was carried out using IBM SPSS software (version 20, IBM Corp, Armonk, New York). The Kaplan-Meier method was used for survival analyses and comparisons were done using the log-rank test. Cox regression analysis (proportional hazards model) was used to evaluate the hazard ratio between groups when analyzed according to factors that may affect survival. The analysis of variance and chi-square $\left(\chi^{2}\right)$ were used for comparisons between groups. All tests were double-sided, and a $P$ value of $\leq .05$ was considered significant. The $95 \%$ confidence intervals are presented in brackets.

\section{RESULTS}

\section{Oncological Outcome}

Mean overall survival (OS) of the 50 patients was 53 months (range, 32-73 months), whereas median OS was 20 months (range, 8-32 months). At last follow-up, 7 patients were still alive. A KaplanMeier analysis of OS is depicted in Figure 1a.

There was no difference regarding survival between patients diagnosed with myeloma/plasmocytoma or lymphoma. Gender, age, location, and the severity of neurological deficits at presentation or the presence of a pathological fracture also had no impact on survival (Table 1). However, patients who had a high blood hemoglobin preoperatively had a superior OS (Figure 1b).

\section{Functional Outcome After Surgical Decompression}

Neurological improvement was noted in 35 patients $(70 \%)$ and preservation of function in 12 $(24 \%)$, whereas 3 patients deteriorated $(6 \%)$. Of the 3 cases of neurologic deterioration after surgery, 1 was due to hematoma formation and secondary nerve injury and another due to intraoperative injury of the spinal cord from the implant, whereas the third was attributed to accidental intraoperative injury of the cord during decompression of the tumor. 
a

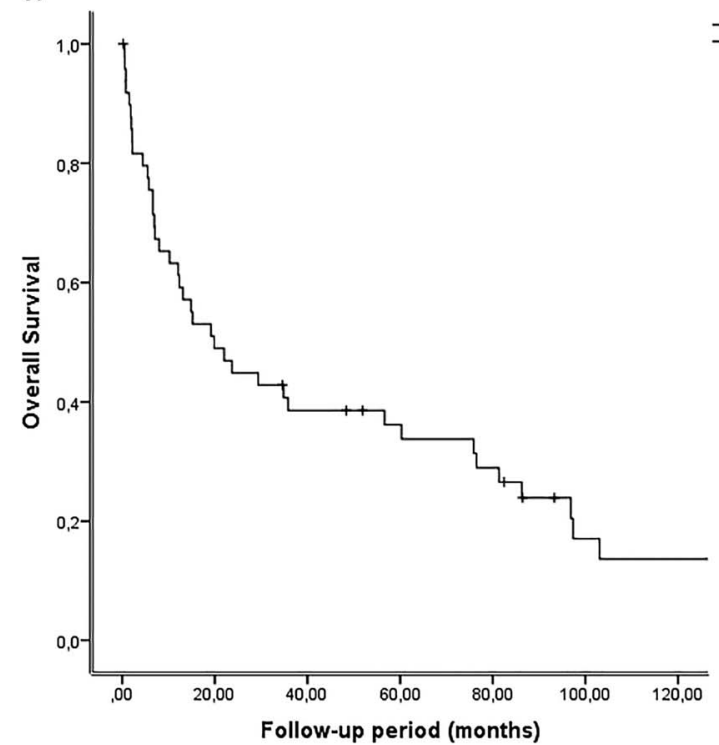

b

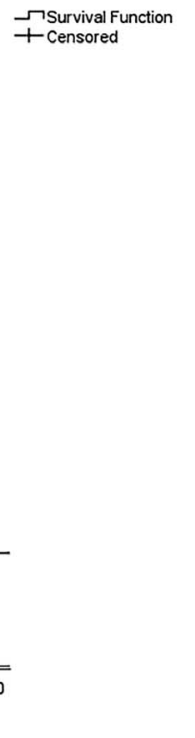

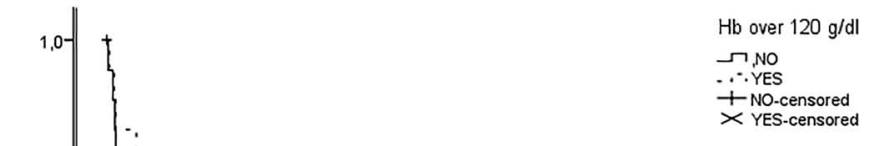

Figure 1. Kaplan-Meier analysis of overall survival of 50 patients with hematological malignancies presenting with metastatic spinal cord compression (a). Patients who have a blood hemoglobin of less the $120 \mathrm{~g} / \mathrm{dL}$ prior to surgery have an inferior prognosis $(P<.001)(\mathrm{b})$.

Time to surgery was associated with the neurological outcome: 35 patients $(70 \%)$ were operated upon within 24 hours; 42 (84\%), within 48 hours; and the remaining $8(16 \%)$, after 48 hours. When individual time periods were analyzed, patients who underwent decompression after 48 hours had a clearly inferior outcome as compared with those who had surgery within 48 hours (Figure 2), whereas outcome was equal irrespective of whether surgery was performed within 24 or 48 hours.

Table 1. Cox-regression analysis for prognostic factors of overall survival in 50 patients presenting with metastatic spinal cord compression due to hematological malignant disease.

\begin{tabular}{|c|c|c|c|}
\hline \multirow[b]{2}{*}{ Factor } & \multicolumn{2}{|c|}{ Overall Survival, \% } & \multirow[b]{2}{*}{$P$ Value } \\
\hline & 1 Year & 5 Year & \\
\hline Age & & & .146 \\
\hline$<65 \mathrm{y}$ & 67 & 51 & \\
\hline$\geq 65 \mathrm{y}$ & 60 & 24 & \\
\hline Sex & & & .596 \\
\hline Male & 65 & 38 & \\
\hline Female & 62 & 34 & \\
\hline Diagnosis & & & .221 \\
\hline Myeloma/plasmocytoma & 71 & 41 & \\
\hline Lymphoma & 47 & 27 & \\
\hline Pathological fracture & & & .480 \\
\hline Yes & 61 & 37 & \\
\hline No & 68 & 37 & \\
\hline Able to walk preoperatively & & & .939 \\
\hline Yes & 67 & 38 & \\
\hline No & 61 & 36 & \\
\hline Location & & & .923 \\
\hline Cervical/thoracic & 65 & 35 & \\
\hline Lumbar & 57 & 43 & \\
\hline Hemoglobin preoperatively & & & .001 \\
\hline$\geq 120 \mathrm{~g} / \mathrm{dL}$ & 75 & 60 & \\
\hline$<120 \mathrm{~g} / \mathrm{dL}$ & 46 & 15 & \\
\hline
\end{tabular}

Ambulatory capacity was restored in 19 of 26 patients $(73 \%)$ who were unable to walk preoperatively. Among these, 18 had surgical treatment within 48 hours of admittance and only 1 after this time period $\left(\chi^{2}=0.043\right)$. Neurological performance also had an impact on prognosis, given that patients who remained totally bedridden after surgery had an inferior overall survival (Figure 3).

The neurological outcome was also dependent on the severity of the initial neurological deficits $\left(\chi^{2}<\right.$ 0.001). Patients who were assessed as Frankel grade $\mathrm{B}$ or $\mathrm{C}$ were more likely to result in neurological

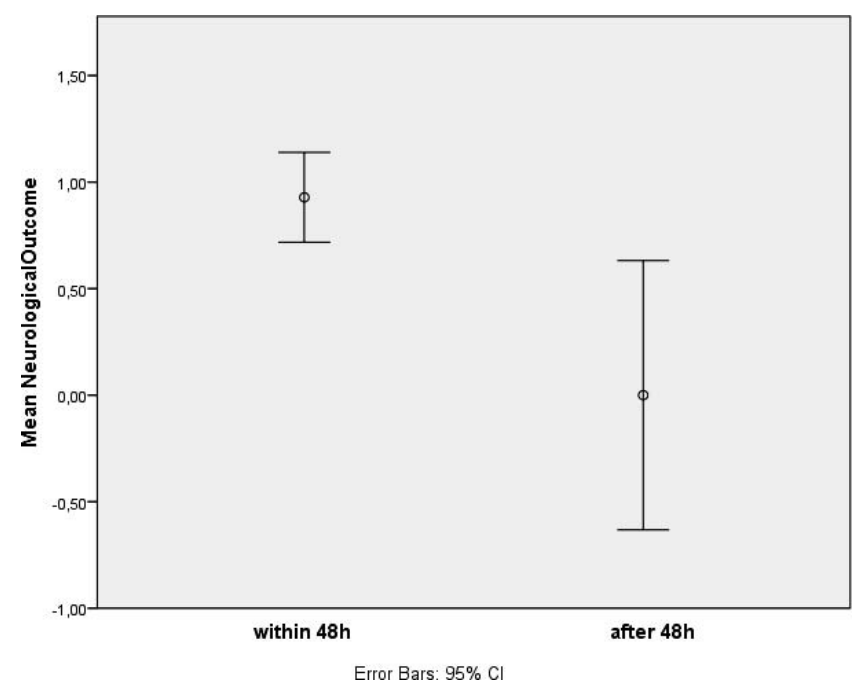

Figure 2. Graphic presentation of the mean neurological outcome calculated as the difference in Frankel scale at first follow-up after decompressive surgery $(P=.001)$. 


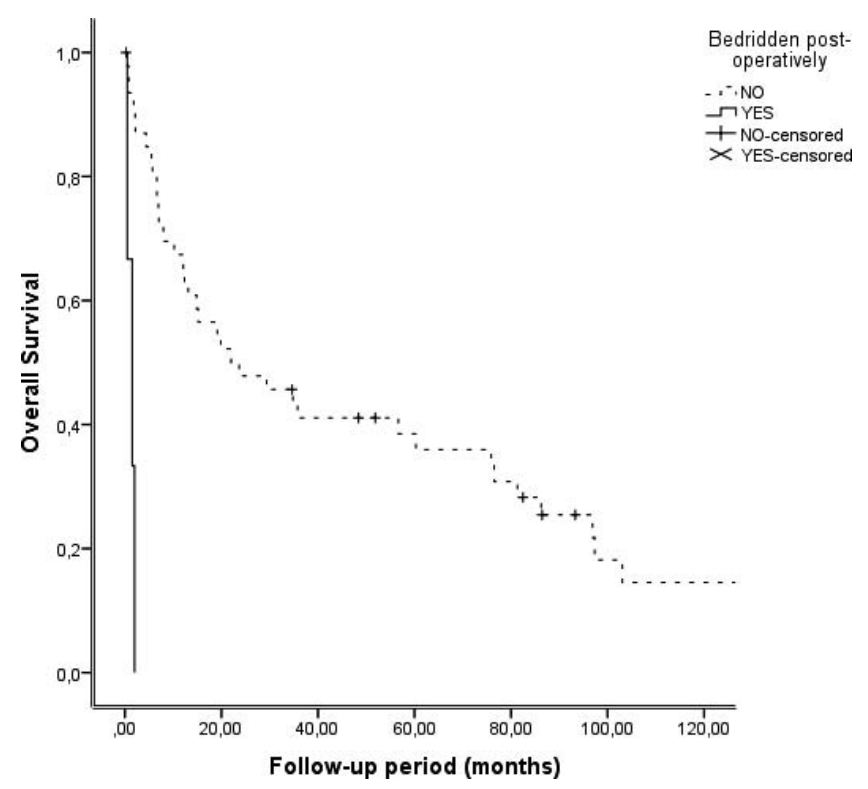

Figure 3. Kaplan-Meier analysis of overall survival of 50 patients with hematological malignancies presenting with metastatic spinal cord compression. Patients who remained totally bedridden after surgery have an inferior prognosis $(P<.001)$.

improvement (7/9 patients and $13 / 15$ patients, respectively). In the case of minor neurological deficits on presentation (Frankel D), 14 of 23 of the patients improved, 6 remained stable, and 3 deteriorated. Of the 2 totally paretic patients (Frankel A), neither became ambulatory but 1 improved to Frankel C. One Frankel E patient retained intact neurological performance postoperatively.

Radiotherapy was not associated with the neurological outcome of this cohort $(P=.920)$.

\section{Analysis of Postoperative Complications}

Complications occurred in 11 (22\%) of surgically treated patients. Wound infection and dehiscence was documented in 5. Two of these presented with late chronic infections requiring extraction of the implants combined with antibiotic treatment until healing. Two patients needed wound debridement and flap reconstruction for healing of the infection. There were 3 cases of postoperative hematoma formation, 2 of which were surgically evacuated. Other observed complications were iatrogenic nerve or dura injuries (2 patients) and systemic complications (sepsis and ileus) in 1 patient.

Neither age $\left(\chi^{2}=1.000\right)$, gender $\left(\chi^{2}=0.498\right)$, presence of a pathological fracture $\left(\chi^{2}=0.498\right)$, nor the use of an implant $\left(\chi^{2}=0.220\right)$ were associated with postoperative complications, whereas patients who had radiotherapy had a higher complication rate $\left(\chi^{2}=0.009\right)$.

There was only one case of secondary operation due to recurrence of neurological symptoms. The early postoperative mortality rate was $8 \%$, given that there were 4 deaths due to cardiovascular compromise and failure in the first 30 days after the operation.

\section{DISCUSSION}

The purpose of the present study was to assess survival and neurological function after surgical treatment for spinal cord compression in patients with lymphoma or myeloma. We found neurological improvement in the vast majority of patients. In our series, neurologic deterioration was due to surgical factors rather than tumor progression and late deformity. We also noted a high rate of postoperative complications, mainly wound-healing problems. Because such complications may imperil successful medical oncological treatment, spinal surgery is only indicated when there is risk of permanent and major neurological impairment.

Our findings, derived from the largest published cohort, support the view that early surgical decompression is associated with a superior neurological recovery. This is in accordance with the data presented by Quraishi et $\mathrm{al}^{16}$ and is generally in keeping with the overall belief in early decompression of the spinal cord that has been mainly based on traumatic injury data. ${ }^{17}$ The fact that there was no major difference between surgery the first or second day after admission can be attributed to the subacute nature of the compression of the spinal cord by epidural tumors. As opposed to traumatic injury, spinal cord compression in cancer patients is generally accompanied by a gradual onset of symptoms and allows for compensatory mechanisms to take place. We, however, acknowledge that the present study has obviously not sufficient power to detect minor differences in the neurologic outcome of patients operated within 24 hours and 48 hours.

Decompressive surgery was effective in cases of pronounced partial neurological impairment (Frankel grades B and C) and remained meaningful in lesser neurological deficits (Frankel D). The numbers in our study were not sufficient to draw conclusions regarding totally paretic patients (Frankel A). Thus, surgical treatment (often combined with radiotherapy) appears particularly effective in restoring deficits and the ambulatory capacity 
in this setting. Of note, we also observed that totally bedridden patients have a poor survival, corroborating similar data by Rehak et al, ${ }^{14}$ which obviously reflects the negative effect of reduced mobility and associated morbidity in the general condition of the patient.

Generally, the complication rate after decompressive surgical treatment was significant, and the mortality rate was not negligible, a finding in accordance with published data. ${ }^{5,7,18}$ The most common postoperative complication was infection, which is also in agreement with previous observations, ${ }^{19}$ and can be attributed to both systemic (cachexia, immunocompromise) and local factors (poor soft tissue coverage of the thoracic spine, irradiation). Even though a combined effect of these factors is certainly anticipated, and many of these are not easily recorded or quantified, radiotherapy had a clear correlation with postoperative complication. Radiotherapy, on the other hand, has a critical role in local control of the disease, and whether the risks outweigh the benefits remains to be shown.

Whether the mortality within the first weeks after surgery was due to the treatment or rather to the primary disease and neurological deficit is difficult to assess. Clearly, mortality among cancer patients with spinal cord compression is high, irrespective of surgical treatment. The finding that patients with near-normal hemoglobin had a better prognosis is obviously indicative of the effect of myelosuppression on the oncological outcome.

Collectively, our findings support the notion that early surgical decompression is associated with good neurological outcome in patients with cord compression from radiosensitive heamatological neoplasia. A favorable neurological outcome appears also to affect patient survival. Decompressive surgery should thus be discussed with the patient when neurological deficits are present, taking into account that the surgical intervention is accompanied by a significant risk of complications.

\section{REFERENCES}

1. Byrne TN. Spinal cord compression from epidural metastases. N Engl J Med. 1992;327(9):614-619. https://doi. org/10.1056/NEJM199208273270907.

2. Dea N, Fisher CG. Evidence-based medicine in metastatic spine disease. Neurol Res. 2014;36(6):524-529. https://doi.org/ 10.1179/1743132814Y.0000000365.

3. Constans JP, de Divitiis E, Donzelli R, Spaziante R, Meder JF, Haye C. Spinal metastases with neurological manifestations. Review of 600 cases. J Neurosurg. 1983;59(1):111-118. https://doi.org/10.3171/jns.1983.59.1.0111.
4. Gilbert RW, Kim JH, Posner JB. Epidural spinal cord compression from metastatic tumor: diagnosis and treatment. Ann Neurol. 1978;3(1):40-51. https://doi.org/10.1002/ana. 410030107.

5. Sørensen S, Børgesen SE, Rohde K, et al. Metastatic epidural spinal cord compression. Results of treatment and survival. Cancer. 1990;65(7):1502-1508.

6. Young RF, Post EM, King GA. Treatment of spinal epidural metastases. Randomized prospective comparison of laminectomy and radiotherapy. J Neurosurg. 1980;53(6):741748. https://doi.org/10.3171/jns.1980.53.6.0741.

7. Sundaresan N, Sachdev VP, Holland JF, et al. Surgical treatment of spinal cord compression from epidural metastasis. $J$ Clin Oncol. 1995;13(9):2330-2335.

8. Harrington KD. Orthopedic surgical management of skeletal complications of malignancy. Cancer. 1997;80(suppl 8):1614-1627.

9. Patchell RA, Tibbs PA, Regine WF, et al. Direct decompressive surgical resection in the treatment of spinal cord compression caused by metastatic cancer: a randomised trial. Lancet. 2005;366(9486):643-648. https://doi.org/10.1016/S01406736(05)66954-1.

10. Falicov A, Fisher CG, Sparkes J, Boyd MC, Wing PC, Dvorak MF. Impact of surgical intervention on quality of life in patients with spinal metastases. Spine (Phila Pa 1976). 2006;31(24):2849-2856. https://doi.org/10.1097/01.brs. 0000245838.37817 .40 .

11. Ibrahim A, Crockard A, Antonietti P, et al. Does spinal surgery improve the quality of life for those with extradural (spinal) osseous metastases? An international multicenter prospective observational study of 223 patients. Invited submission from the Joint Section Meeting on Disorders of the Spine and Peripheral Nerves, March 2007. J Neurosurg Spine. 2008;8(3):271-278. https://doi.org/10.3171/SPI/2008/8/3/ 271.

12. Quan GMY, Vital J-M, Aurouer N, et al. Surgery improves pain, function and quality of life in patients with spinal metastases: a prospective study on 118 patients. Eur Spine J. 2011;20(11):1970-1978. https://doi.org/10.1007/s00586011-1867-6.

13. Dürr HR, Wegener B, Krödel A, Müller PE, Jansson V, Refior HJ. Multiple myeloma: surgery of the spine: retrospective analysis of 27 patients. Spine (Phila Pa 1976). 2002;27(3):320-324, discussion 325-326.

14. Rehak S, Maisnar V, Malek V, et al. Diagnosis and surgical therapy of plasma cell neoplasia of the spine. Neoplasma. 2009;56(1):84-87.

15. Jansson K-A, Bauer HCF. Survival, complications and outcome in 282 patients operated for neurological deficit due to thoracic or lumbar spinal metastases. Eur Spine J. 2006;15(2):196-202. https://doi.org/10.1007/s00586-004-0870-6.

16. Quraishi NA, Rajagopal TS, Manoharan SR, Elsayed S, Edwards KL, Boszczyk BM. Effect of timing of surgery on neurological outcome and survival in metastatic spinal cord compression. Eur Spine J. 2013;22(6):1383-1388. https://doi. org/10.1007/s00586-012-2635-y.

17. Anderson KK, Tetreault L, Shamji MF, et al. Optimal timing of surgical decompression for acute traumatic central cord syndrome: a systematic review of the literature. Neurosurgery. 2015;77(suppl 4):S15-S32. https://doi.org/10.1227/NEU. 0000000000000946 .

18. Li H, Gasbarrini A, Cappuccio M, et al. Outcome of 
excisional surgeries for the patients with spinal metastases. Eur Spine J. 2009; 18(10):1423-1430. https://doi.org/10.1007/s00586009-1111-9.

19. Quraishi NA, Rajabian A, Spencer A, et al. Reoperation rates in the surgical treatment of spinal metastases. Spine J. 2015;15(suppl 3):S37-S43. https://doi.org/10.1016/j.spinee. 2015.01.005.

Disclosures and COI: The authors received no funding for this study and report no conflicts of interest.

Corresponding Author: Panagiotis Tsagozis,
Bsc, MD, PhD, Department of Orthopaedic Surgery, Karolinska University Hospital, 17176 Stockholm, Sweden. Phone: 0046851770000; Email: panagiotis.tsagkozis@sll.se.

Published 30 April 2019

This manuscript is generously published free of charge by ISASS, the International Society for the Advancement of Spine Surgery. Copyright (C) 2019 ISASS. To see more or order reprints or permissions, see http://ijssurgery.com. 